\title{
Estrategias pedagógicas y didácticas para el desarrollo de las inteligencias múltiples y el aprendizaje autónomo
}

\author{
María Cristina Gamboa Mora ${ }^{1}$ \\ Yenny García Sandoval ${ }^{2}$ \\ Marlén Beltrán Acosta ${ }^{3}$
}

\begin{abstract}
Resumen
Esta contribución presenta la valoración de las estrategias pedagógicas y didácticas implementadas en una institución educativa del municipio de Ubalá, Inspección Laguna Azul, Bogotá-Colombia. Describe su articulación con la propuesta de Howard Gardner en 1983, referida al desarrollo de las inteligencias múltiples y el aprendizaje autónomo, a través del reconocimiento de las formas individuales de aprendizaje y la estimulación de procesos cognitivos que conllevan al aprendizaje y construcción del espacio.

El propósito fue concientizar a estudiantes y docentes respecto de la significación que tienen las estrategias pedagógicas y didácticas desde la propuesta de Gardner y la importancia de una planeación de estrategias cotidianas que a partir de su reconocimiento, se transforman en nuevas formas activas y creativas que estimulan la motivación hacia el conocimiento, facilitan el proceso de aprendizaje de los estudiantes, fortalecen el desarrollo integral del individuo y promueven las inteligencias múltiples.
\end{abstract}

Palabras clave: aprendizaje autónomo, estrategias pedagógicas, inteligencias múltiples.

1 Magister en docencia de la química. Estudiante de doctorado en Innovación e Investigación en Didáctica, UNED. Docente Escuela Ciencias de la Educación ECEDU- UNAD. Grupo de investigación Ambientes de Enseñanza Aprendizaje de las Ciencias Básicas. maria.gamboa@unad.edu.co

2 Especialista en enseñanza de la Biología. Estudiante de maestría en Educación. UPN. Docente Escuela Ciencias de la Educación ECEDU- UNAD. Grupo de investigación Ambientes de Enseñanza Aprendizaje de las Ciencias Básicas yenny. garcia@unad.edu.co

3 Especialista en aprendizaje autónomo. Universidad Nacional Abierta y a Distancia UNAD. gloriabel29@hotmail.com 


\title{
Teaching and didactics strategies for the development of multiple intelligence and autonomous learning
}

\begin{abstract}
This study presents an assessment of the teaching and didactics strategies implemented in a School, located in the city of Ubalá, Inspection of Laguna Azul, Bogotá-Colombia. The articulation is described based on Howard Gardner proposal (1983) which relates to the development of multiple intelligences and autonomous learning through the individual forms of learning recognition and cognitive processes stimulation that lead to learning and knowledge construction.

The main goal was to make students and teachers aware of the teaching strategies significance from Gardner's proposal. Also of the importance of strategic planning based on daily life environment which after being recognized becomes an active and creative new ways that stimulate the motivational process towards knowledge. Thus facilitate student's learning process, strengthen the development of the individual and promote multiple intelligences.
\end{abstract}

Key words: Autonomous learning, multiple intelligences, teaching strategies. 


\section{Introducción y estado de la cuestión}

\section{Estrategias pedagógicas y didácticas}

Las estrategias pedagógicas son todas las acciones realizadas por el docente, con el fin de facilitar la formación y el aprendizaje de los estudiantes. "Componen los escenarios curriculares de organización de las actividades formativas y de la interacción del proceso enseñanza y aprendizaje donde se logran conocimientos, valores, prácticas, procedimientos y problemas propios del campo de formación". (Bravo, 2008, p.52). Las estrategias pedagógicas suministran invaluables alternativas de formación que se desperdician por desconocimiento y por la falta de planeación pedagógica, lo que genera monotonía que influye negativamente en el aprendizaje.

Existe una articulación directa entre las estrategias pedagógicas y las estrategias didácticas, las primeras son la base para la generación de las segundas, porque van en concordancia con el principio pedagógico fundante. Las estrategias didácticas son el resultado de la concepción de aprendizaje en el aula o ambiente diseñado con esta finalidad y de la concepción que se tiene sobre el conocimiento, algunos hablan de transmitir y otros de construir, dichas concepciones determinan su actuación en el aula. Actualmente, las exigencias del mundo globalizado hacen necesaria la implementación de estilos y maneras de enseñanza y que se presenten de formas diferentes los contenidos, para que el aprendizaje sea dinámico y creativo, y despierte el interés de los estudiantes como actores de dicho proceso.

Gamboa (2009), indica que la planeación debe propender por la formación científica de los estudiantes a través de la selección de estrategias, la unificación de planes de curso por área, las competencias, la definición de investigación en el aula y las acciones pedagógicas y didácticas, ya que así se favorecerá el proceso de enseñanza aprendizaje.

Gamboa (2004), señala que los requerimientos plantean la necesidad de un elemento primordial del aprendizaje, la autoeducación y el autodidactismo; en este orden de ideas, el profesor de hoy debe organizar y dirigir el proceso de construcción del conocimiento en primer lugar y, posteriormente, se convertirá en orientador y acompañante del proceso y fuente alterna de información de los aspectos esenciales (que ha construido a lo largo de su experiencia profesoral).

Entre los factores decisivos en el aprendizaje, están la parte sensorial y la parte emocional, ya que son elementos que elevan el nivel de motivación en los estudiantes. En el proceso de enseñanza-aprendizaje se hace necesario no sólo lograr la motivación en el estudiante, sino también, construir conceptos 
que puedan ser utilizados para generar una posible solución a una situación problémica que debe resolver, esta vía se describe en la figura 1 .

Gamboa (2004), señala que un problema o una situación problémica es una situación ante la cual inicialmente se está perdido, una situación abierta que no necesariamente tiene magnitudes numéricas y ante la cual, se busca primero que pueda formularse en forma de pregunta; posteriormente, formular hipótesis que respondan a la situación y, finalmente resolver con éxito a través del empleo de los conocimientos previos; los consultados, los socializados y las actividades prácticas o comparativas que se requieran.

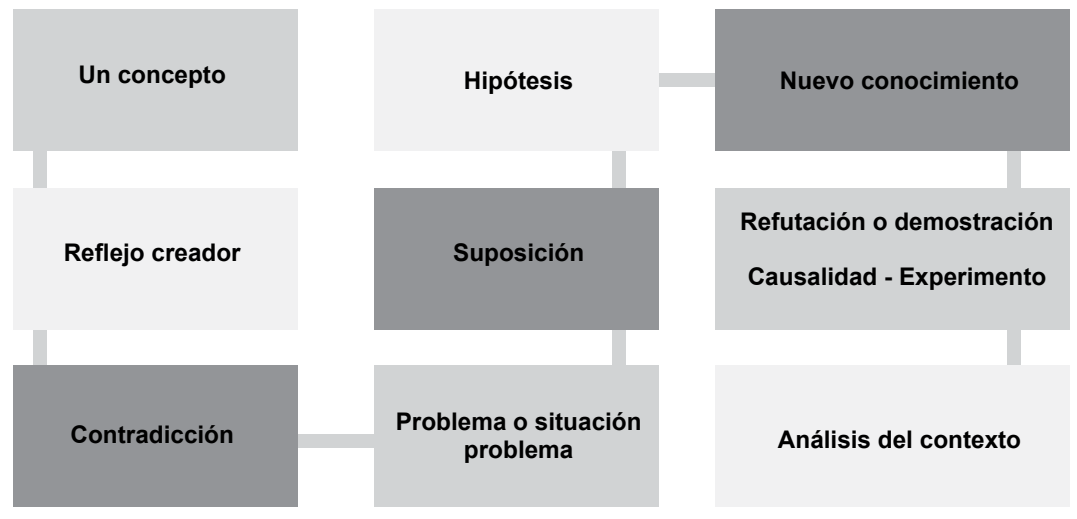

Figura 1. Vía para la construcción de conocimientos.

Fuente: diseño con base en Gamboa, M. (2004). Diagnóstico sobre las concepciones que tienen los profesores y estudiantes de las Facultades de Salud e Ingeniería de la Fundación Universitaria Manuela Beltrán acerca de las prácticas de Laboratoria de Química. Bogotá: UNP

\section{La inteligencia}

En su sentido más amplio, representa la capacidad cerebral por la cual se logra penetrar en la comprensión de las cosas adoptando el mejor camino; la formación de ideas, el juicio y el razonamiento son habitualmente señalados como actos esenciales de la inteligencias, como facultad de comprender. Es indudable que la inteligencia no constituye sólo un elemento neurológico aislado, independiente del ambiente. Pierre Lévy (1993), desarrolló la noción de ecología cognitiva, en la cual muestra que cada individuo no pensaría lejos de la colectividad, desprovisto de un ambiente; todas nuestras inteligencias no son nada más que fragmentos componentes de una ecología cognitiva que nos engloba. Por lo tanto, el individuo no sería inteligente sin su lengua; su herencia cultural, su ideología, su creencia, su escritura, unos métodos intelectuales y otros medios del ambiente. 
Antunes (2000), afirma que no existe una inteligencia general que crezca o se estanque, sino un catálogo múltiple de aspectos de la inteligencia, algunos más sensibles que otros a la evolución mediante los estímulos adecuados. Es viable afirmar, con evidencias científicas claras, que la inteligencia humana puede aumentarse básicamente en los primeros años de vida, incluso admitiendo que las reglas de ese aumento estén comprometidas por restricciones genéticas, pues la inteligencia de un individuo es fruto de una carga genética que va mucho más allá de la de los abuelos. En efecto, algunos detalles de la estructura de la inteligencia pueden ser transformados con estímulos significativos aplicados en momentos cruciales del desarrollo humano. Ese aumento es más intenso para la construcción de algunas operaciones que para otras.

La inteligencia puede deteriorase y esto se genera con frecuencia por falta de estímulos más que por razones de índole biológica. Cada inteligencia tiene su ventana de oportunidades claramente definida $\mathrm{y}$, aunque esas ventanas se abren y se cierren al mismo tiempo para todas las personas, su apertura y su cierre dependen mucho de cada inteligencia en especial. Los circuitos cerebrales maduran en diferentes periodos de la vida, destacándose la importancia del estímulo durante la infancia.

\section{Las inteligencias múltiples}

Investigaciones de Neurobiología sugieren la presencia de zonas en cerebro humano que corresponden a determinados espacios de cognición: "Como si un punto de cerebro representase a un sector que albergase una forma especifica de competencia y de procesamiento de informaciones" (Antunes, 2.000, p.15).

El proyecto Harvard sobre inteligencia ha permitido integrar estudios neurológicos, psicológicos y culturales de gran importancia. La investigación neurológica permitió determinar las áreas cerebrales básicas donde residen los tipos de inteligencia. Los estudios del cirujano francés Paul Broca en 1961, conllevaron a descubrir el área del cerebro responsable de la producción del lenguaje. Dicho investigador atendió un paciente que podía entender el lenguaje pero no lo podía hablar, después de su muerte examinó su cerebro y encontró una lesión en el lóbulo frontal izquierdo, con otras constataciones, Broca concluyó que la región Broca está relacionada con el habla. El neurólogo Carl Wernicke en 1874, localizó el área asociada a la comprensión del lenguaje hablado o escrito, la cual lleva su nombre.

De acuerdo con la teoría de Gardner (1983), los seres humanos poseen en mayor o menor medida tipos de inteligencia que le permiten resolver problemas, Gardner ha hecho durante más de veinte años reajustes y reformulaciones a su teoría, para 2006 se habían reportado en total 11 inteligencias; las siete 
iniciales (lingüística, lógico-matemática, musical, cenestésica-corporal, espacial, interpersonal, interpersonal), la octava corresponde a la naturalista, como aporte del profesor brasileño Nilson Machado. La novena es la pictórica; las nuevas inteligencias producto de las investigaciones reportan la sexual, la digital que hace mención a la habilidades para manejar las nuevas tecnologías y, finalmente, la existencial o espiritual. "Otros como Saturnino de la Torre, hablan de inteligencia creativa. Hay quienes consideran la intuición como otro tipo de inteligencia y la habilidad culinaria como una forma especial de inteligencia” (Ander, 2006, p.4).

Como la localización cerebral de esos puntos neurales no constituye una tarea fácil, Gardner (1983) indica ocho señales o criterios que considera esenciales para que una competencia pueda ser incluida como una inteligencia. Estas serían:

- Identificación de la morada de la inteligencia por daño cerebral: es válido en la medida en que el daño causado a una parte del cerebro puede afectar a las habilidades inherentes a esa inteligencia.

- Existencia de individuos excepcionales en ámbitos específicos de la solución de problemas o de la creación: personas que presentan graves limitaciones en ciertos niveles de inteligencia y una excepcionalidad en otras, permiten caracterizar esas inteligencias.

- Gatillo neural preparado para dispararse en determinados tipos de información interna o externa: el criterio se basaría en la capacidad momentánea de algunas personas para "disparar" su inteligencia a partir de estímulos.

- Susceptibilidad a la modificación de la inteligencia mediante el entrenamiento: las inteligencias no nacen preparadas, aunque unas personas puedan presentar niveles más altos que otras en esta o aquella inteligencia.

- Una historia de plausibilidad evolutiva: algunas inteligencias específicas se vuelven más plausibles en la medida en que es posible la localización de antecedentes evolutivos.

- Exámenes específicos mediante tareas psicológicas experimentales: ciertas investigaciones psicológicas pueden, por ejemplo, estudiar la especificidad del procesamiento lingüístico, espacial o musical lo que permite que se pueda investigar la autonomía de una inteligencia.

- Apoyo de exámenes psicométricos: los resultados de experiencias psicométricas muestran claros indicios de inteligencias específicas, es común en exámenes de esa índole la identificación de la extraordinaria habilidad lógico-matemática. 
- Creación de un sistema simbólico específico: de modo general, se puede distinguir ocho o nueve sistemas simbólicos que identifican el aislamiento de esas inteligencias. Es muy posible que una de las más importantes características de la inteligencia humana sea su orientación natural hacia la incorporación de un sistema simbólico específico.

En líneas generales, esos ocho criterios permiten identificar el elenco de las inteligencias múltiples y los medios por los que pueden ser juzgadas.

Tabla 1. Inteligencias propuestas por Gardner Vs estrategias didácticas que se pueden proyectar en la planeación pedagógica

\begin{tabular}{|c|c|c|}
\hline Inteligencia & Características & $\begin{array}{l}\text { Estrategias Didácticas que se pueden } \\
\text { proyectar en la planeación pedagógica }\end{array}$ \\
\hline $\begin{array}{l}\text { Lógico } \\
\text { Matemática }\end{array}$ & $\begin{array}{c}\text { La inteligencia lógico-matemática se observa en } \\
\text { la habilidad para el desarrollo del cálculo, para } \\
\text { usar los números de forma efectiva y razonar } \\
\text { adecuadamente. }\end{array}$ & $\begin{array}{l}\text { Modelamiento, club de revistas, resolución de } \\
\text { problemas, acertijos; comparación y contraste, } \\
\text { aprendizaje basado en problemas (ABP), } \\
\text { deducción e inducción. }\end{array}$ \\
\hline Lingüística & $\begin{array}{l}\text { Esta inteligencia se basa en la capacidad para } \\
\text { disponer palabras de manera efectiva, sea en } \\
\text { forma oral o de manera escrita, representa un } \\
\text { instrumento esencial para la supervivencia del } \\
\text { ser humano moderno; el lenguaje constituye el } \\
\text { mecanismo más importante y algunas veces, } \\
\text { el único de la comunicación. A pesar de ello, } \\
\text { algunas personas no utilizan completamente } \\
\text { ese potencial, debido al limitado vocabulario que } \\
\text { conocen. }\end{array}$ & $\begin{array}{l}\text { Debates, Mesas redondas, Preguntas, } \\
\text { Exposiciones, Lecturas dirigidas, Lectura } \\
\text { autorregulada, Descripción, Reseña, } \\
\text { Resumen y Narración. }\end{array}$ \\
\hline Espacial & $\begin{array}{c}\text { Atunes (2000) señala que esta inteligencia } \\
\text { envuelve la sensibilidad al color, la línea, la } \\
\text { forma, el espacio y las relaciones que concurren } \\
\text { entre estos elementos. Incluye la capacidad de } \\
\text { visualizar, de plasmar de manera gráfica ideas } \\
\text { visuales o espaciales. }\end{array}$ & $\begin{array}{c}\text { Ajedrez, ideogramas, mentefactos, mapas } \\
\text { conceptuales, flujograma o diagrama de flujo } \\
\text { y dibujos. }\end{array}$ \\
\hline Pictórica & $\begin{array}{c}\text { Capacidad de expresión mediante trazo, dibujo o } \\
\text { caricatura, hacer bocetos, entre otros. }\end{array}$ & $\begin{array}{l}\text { Dibujos, imágenes de personas y lugares; } \\
\text { asociar objetos y colores, delinear y modelar } \\
\text { en diferentes materiales figuras. }\end{array}$ \\
\hline Musical & $\begin{array}{l}\text { Para Gadner, se expresa a través de tres } \\
\text { competencias básicas: un sentido para los tonos } \\
\text { (frecuencias), un sentido para el ritmo y un } \\
\text { sentido para las tonalidades (Ander, 2006, p.7). }\end{array}$ & $\begin{array}{l}\text { Lectura de notación musical, composición } \\
\text { musical, composición rondas, coplas y } \\
\text { canciones. }\end{array}$ \\
\hline Sexual & $\begin{array}{l}\text { Está relacionada con la manera de vincularse al } \\
\text { placer erótico/sexual (Ander, 2006, p.6). }\end{array}$ & $\begin{array}{c}\text { Actividades de socialización, con participación } \\
\text { de diversos géneros. }\end{array}$ \\
\hline Digital & $\begin{array}{l}\text { Habilidad para manejarse con las nuevas } \\
\text { tecnologías (Ander, 2006, p.6). }\end{array}$ & $\begin{array}{c}\text { Foros, chats, actuaciones en mundos virtuales } \\
\text { y en general uso herramientas web. }\end{array}$ \\
\hline $\begin{array}{l}\text { Corporal } \\
\text { cinestésica }\end{array}$ & $\begin{array}{c}\text { Control de movimientos corporales Habilidades } \\
\text { y destrezas manuales para realizar actividades } \\
\text { detalladas y en pequeñas dimensiones. }\end{array}$ & Dramatizaciones, danzas, deporte y juegos. \\
\hline Interpersonal & $\begin{array}{l}\text { Reconocimiento de sí mismo y de sus procesos } \\
\text { intelectuales y las emociones. } \\
\text { Autoestima y autoconocimiento. }\end{array}$ & Trabajo en equipo, Juego de roles y Reflexión. \\
\hline Interpersonal & $\begin{array}{l}\text { Capacidad empática y habilidades sociales. } \\
\text { Esta inteligencia permite leer al otro en una } \\
\text { relación social, se leen las intenciones y } \\
\text { pretensiones de los otros. }\end{array}$ & Trabajo en equipo, juego de roles y reflexión. \\
\hline
\end{tabular}




\begin{tabular}{|c|c|c|}
\hline Inteligencia & Características & $\begin{array}{c}\text { Estrategias Didácticas que se pueden } \\
\text { proyectar en la planeación pedagógica }\end{array}$ \\
\hline Naturalista & $\begin{array}{c}\text { Capacidad que se asocia al reconocimiento de } \\
\text { las especies en un entorno natural y establecer } \\
\text { diferencias entre ellas. } \\
\text { Capacidad para discriminar. }\end{array}$ & $\begin{array}{c}\text { Trabajo de Campo, Observación del entorno, } \\
\text { contexto natural y Salidas ecológicas. }\end{array}$ \\
\hline $\begin{array}{c}\text { Existencial o } \\
\text { espiritual }\end{array}$ & $\begin{array}{c}\text { Sentido de la existencia (Ander, 2006, p.6) } \\
\text { Escala de valores. }\end{array}$ & $\begin{array}{c}\text { Trabajo en equipo, actividades sociales y } \\
\text { religiosas. }\end{array}$ \\
\hline
\end{tabular}

Fuente: Autores. Diseño con base en la teoría de Gardner.

Es importante señalar que los test de coeficiente intelectual (CI) tienen como base la inteligencia lingüística y el razonamiento matemático, pero en los procesos de aprendizaje se pretende que a través de la planeación pedagógica y el conocimiento de la teoría de las inteligencias múltiples, los docentes seleccionen actividades que potencialicen todas las inteligencias generando un desarrollo integral de sus estudiantes.

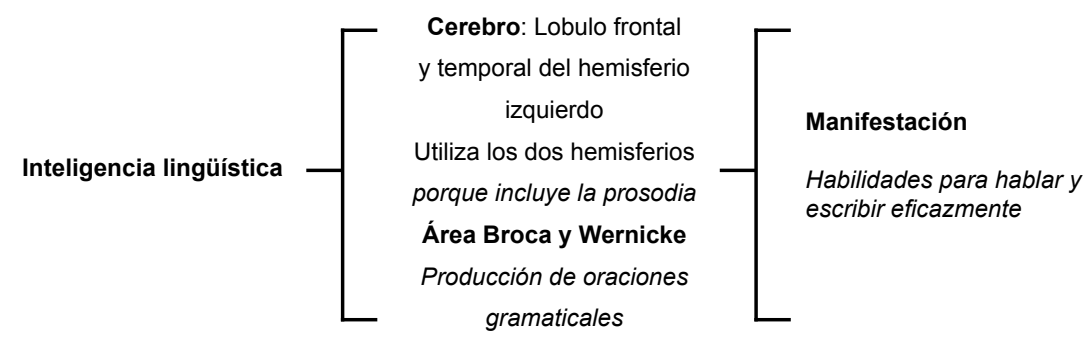

Figura 2. Descripción Inteligencia lingüística. Nota: Diseño con base en la teoría de Gardner.

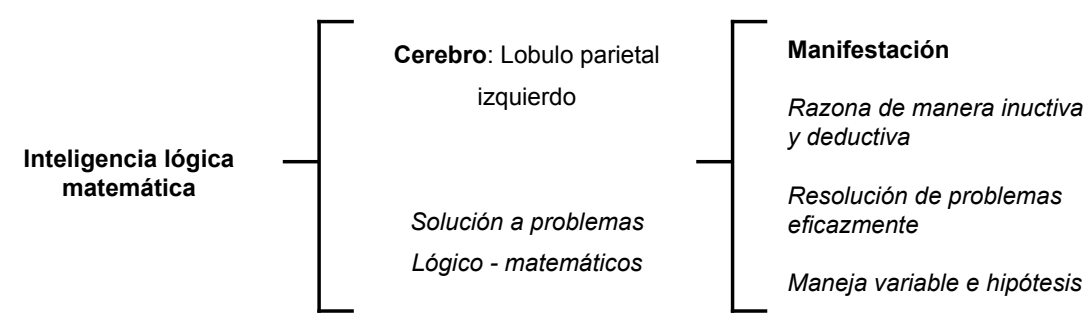

Figura 3. Descripción Inteligencia Lógico Matemática. Nota: Diseño con base en la teoría de Gardner.

Todos los seres humanos pueden potencializar sus inteligencias y eso se conoce como la ventana de oportunidades; las fibras nerviosas capaces de activar el cerebro necesitan ser construidas, y lo son por los retos y estímulos a que está sometido el ser humano; el cerebro al inicio es una masa casi inerte sin las experiencias que le llevan al aprendizaje. En un recién nacido los dos hemisferios del cerebro aún no están especializados, eso irá ocurriendo 
lentamente hasta los cinco años y rápidamente hasta los dieciséis años, pero de modo desigual en cada hemisferio y para cada inteligencia.

A continuación se presentan los períodos de mayor apertura en cada una de las ventanas conocidas. Antunes (2000) señala que el impedimento del aprendizaje se manifiesta después de los 72 años.

Tabla 2. Relación entre la inteligencia y el aprendizaje

\begin{tabular}{|c|c|c|c|}
\hline Inteligencias & $\begin{array}{l}\text { Apertura de la } \\
\text { ventana }\end{array}$ & Lo que ocurre en el cerebro & "Gimnasias" \\
\hline $\begin{array}{l}\text { Espacial (lado } \\
\text { derecho) }\end{array}$ & De 5 a 10 años. & $\begin{array}{l}\text { Regulación del sentido de } \\
\text { lateralidad y direccionalidad. } \\
\text { Perfeccionamiento de la } \\
\text { coordinación motriz y la } \\
\text { percepción del cuerpo en el } \\
\text { espacio. }\end{array}$ & $\begin{array}{c}\text { Ejercicios físicos y juegos operatorios } \\
\text { que exploran la noción de derecha, } \\
\text { izquierda, arriba y abajo. Natación, judo y } \\
\text { alfabetización cartográfica. }\end{array}$ \\
\hline $\begin{array}{l}\text { Lingüística o } \\
\text { verbal (lado } \\
\text { izquierdo) }\end{array}$ & $\begin{array}{l}\text { Desde el } \\
\text { nacimiento hasta } \\
\text { los } 10 \text { años. }\end{array}$ & $\begin{array}{c}\text { Conexión de los circuitos que } \\
\text { transforman los sonidos en } \\
\text { palabras. }\end{array}$ & $\begin{array}{l}\text { Los niños necesitan oír muchas palabras } \\
\text { nuevas, participar en conversaciones } \\
\text { estimulantes, construir con palabras } \\
\text { imágenes sobre composición de objetos, } \\
\text { aprender, cuando sea posible, una lengua } \\
\text { extranjera. }\end{array}$ \\
\hline $\begin{array}{l}\text { Sonora o musical } \\
\text { (lado derecho) }\end{array}$ & De 3 a 10 años. & $\begin{array}{l}\text { Las zonas del cerebro } \\
\text { vinculadas a los movimientos de } \\
\text { los dedos de la mano izquierda } \\
\text { son muy sensibles y facilitan la } \\
\text { utilización de instrumentos de } \\
\text { cuerda. }\end{array}$ & $\begin{array}{l}\text { Cantar junto con el niño y jugar a } \\
\text { "aprender a escuchar" la musicalidad de } \\
\text { los sonidos naturales y de las palabras } \\
\text { son estímulos importantes, como también } \\
\text { el habituarse a dejar un } C D \text {, con música } \\
\text { suave, cuando el niño esté comiendo, } \\
\text { jugando o incluso durmiendo. }\end{array}$ \\
\hline $\begin{array}{l}\text { Cinestésica } \\
\text { corporal (lado } \\
\text { izquierdo) }\end{array}$ & $\begin{array}{l}\text { Desde el } \\
\text { nacimiento hasta } \\
\text { los } 506 \text { años. }\end{array}$ & $\begin{array}{l}\text { Asociación entre mirar un objeto } \\
\text { y agarrarlo, así como paso de } \\
\text { objetos de una mano a la otra. }\end{array}$ & $\begin{array}{l}\text { Desarrollar juegos que estimulen el tacto, } \\
\text { el gusto y el olfato. Simular situaciones } \\
\text { de mímica y jugar con la interpretación } \\
\text { de los movimientos. Promover juegos y } \\
\text { actividades motoras diversas. }\end{array}$ \\
\hline $\begin{array}{l}\text { Personales (intra } \\
\text { e interpersonal) } \\
\text { (lóbulo frontal) }\end{array}$ & $\begin{array}{l}\text { Desde el } \\
\text { nacimiento hasta } \\
\text { la pubertad. }\end{array}$ & $\begin{array}{l}\text { Los circuitos del sistema límbico } \\
\text { comienzan a conectarse y } \\
\text { se muestran muy sensibles a } \\
\text { estímulos provocados por otras } \\
\text { personas. }\end{array}$ & $\begin{array}{l}\text { Abrazar al niño cariñosamente, jugar } \\
\text { bastante. Compartir su admiración por } \\
\text { los descubrimientos. Son importantes los } \\
\text { mimos y estímulos dosificados y en el } \\
\text { momento oportuno. }\end{array}$ \\
\hline $\begin{array}{l}\text { Lógico- } \\
\text { matemática } \\
\text { (lóbulos } \\
\text { parietales } \\
\text { izquierdos) }\end{array}$ & De 1 a 10 años. & $\begin{array}{l}\text { El conocimiento matemático } \\
\text { procede inicialmente de las } \\
\text { acciones del niño sobre los } \\
\text { objetos del mundo (cuna, } \\
\text { chupete, sonajero) y evoluciona } \\
\text { hacia sus expectativas } \\
\text { sobre cómo esos objetos } \\
\text { se comportarán en otras } \\
\text { circunstancias. }\end{array}$ & $\begin{array}{l}\text { Acompañar con atención la evolución } \\
\text { de las funciones simbólicas hacia las } \\
\text { motoras. Ejercicios con actividades } \\
\text { sonoras que perfecciones el razonamiento } \\
\text { matemático. Estimular dibujos y facilitar el } \\
\text { descubrimiento de las diferentes gamas } \\
\text { en todas las fotos y dibujos mostrados. }\end{array}$ \\
\hline $\begin{array}{l}\text { Pictórica (lado } \\
\text { derecho) }\end{array}$ & $\begin{array}{l}\text { Desde el } \\
\text { nacimiento hasta } \\
\text { los } 2 \text { años. }\end{array}$ & $\begin{array}{l}\text { La expresión pictórica está } \\
\text { asociada con la función visual } \\
\text { y, en ese corto periodo de } 2 \\
\text { años, se conectan todos los } \\
\text { circuitos entre la retina y la zona } \\
\text { del cerebro responsable de la } \\
\text { visión. }\end{array}$ & $\begin{array}{l}\text { Estimular la identificación de colores. } \\
\text { Utilizar figuras, asociándolas con } \\
\text { las palabras descubiertas. Juego de } \\
\text { interpretación de imágenes. Aportar } \\
\text { figuras de revistas y estimular el uso de } \\
\text { las abstracciones en las interpretaciones. }\end{array}$ \\
\hline
\end{tabular}




\section{Pedagogía para el aprendizaje autónomo}

Es un proceso mediante el cual los actores del proceso educativo detectan sus necesidades de aprendizaje, formulan sus propios objetivos, identifican los recursos necesarios para aprender y las estrategias didácticas a emplear, se evalúa el proceso de enseñanza aprendizaje en todos sus momentos, antes, durante y después del acto educativo. Entre las principales características pueden mencionarse: responsabilidad, claridad de objetivos, autonomía y ritmo propio de aprendizaje:

"La autonomía se ha interpretado, sobre todo a partir de la Ilustración $y$ del texto de Immanuel Kant al respecto, como uno de los síntomas de madurez del ser humano. El hombre plenamente desarrollado no necesita recibir las normas de fuera sino que es capaz de dárselas a sí mismo. Evidentemente, esto no es algo que se logre de la noche a la mañana, sino que, se podría decir que es tarea para toda una vida, bajo esta visión, la Universidad promueve al estudiante en el logro de su mayoría de edad a través de la autorregulación, el trabajo independiente, y el desarrollo de actividades académicas y sociales que implican la autodisciplina" (UNAD, 2011, p.53)

En este proceso, el papel del docente es muy importante diseñando estrategias didácticas que favorezcan el aprendizaje para así lograr que cada estudiante sea artífice y competente ante sus propias necesidades. La estrategia pedagógica del aprendizaje autónomo, tiene en cuenta a la persona como centro del proceso, desarrolla sus capacidades en el medio social y permite aprender a aprender y tener control en el dominio de sus procesos cognitivos.

Finalmente, autonomía significa que la persona puede fijar unas normas que puede elegir por sí mismo para ser cumplidas y respetadas. En otras palabras, la autonomía se relaciona con la capacidad que tiene una persona para elegir lo que es valioso para ella, es decir, para realizar elecciones en sintonía con su autorrealización

“...la autodirección en el aprendizaje es una mezcla de todas las fuerzas tanto interiores como exteriores de la persona que insistan en la aceptación por parte del estudiante de una responsabilidad cada vez mayor teniendo en cuenta las decisiones asociadas al proceso de aprendizaje... "( Brockett y Hiemtra, 1993, p.24).

Las estrategias didácticas que se planean dentro de la pedagogía para el aprendizaje autónomo deben promover las siguientes habilidades, de acuerdo con la Organización para la Cooperación y el desarrollo económico (OCDE, 
2010): pensamiento crítico, aprender a aprender, trabajo en equipo, manejo adecuado de las Tecnologías de la Información y la Comunicación (TIC), capacidad para hacer tareas y solucionar problemas, respeto por el otro, entre otras.

\section{Metodología}

El proyecto se inscribe dentro de la metodología de Investigación Acción Participativa (IAP), por cuanto se asume una posición crítica y reflexiva de la realidad educativa de un colegio del municipio de Ubalá y luego se interviene la comunidad con el fin de generar una transformación en beneficio de todos los actores educativos.

\section{Reconocimiento del Contexto}

La Institución Educativa objeto de estudio es de carácter oficial, ubicada en el municipio Ubalá, Inspección Laguna Azul, Bogotá-Colombia; cuenta con una población de 160 estudiantes y desarrolla sus actividades en jornada diurna. La población estudiantil proviene de los estratos 1 y 2 , se presenta heterogeneidad en los estilos de vida, cultura y convivencia de acuerdo con el entorno en el que se encuentran inmersos. Los padres de familia tienen diferentes ocupaciones, entre las cuales se encuentran: madres cabezas de hogar, empleadas domésticas, ganaderos, agricultores y en menor escala, algunos de ellos se dedican a la minería.

\section{Problemática}

La implementación de una pedagogía tradicional hace que el proceso de enseñanza y aprendizaje se vuelva monótono y poco motivador para los estudiantes, lo que impide el desarrollo de la creatividad al igual que muchos de sus gustos y sus preferencias por determinada actividad. De acuerdo con lo anterior, este proyecto se ve como la oportunidad de implementar nuevas estrategias pedagógicas para fortalecer el aprendizaje y que a su vez cada uno de los estudiantes descubra sus verdaderas potencialidades para que su formación sea integral en el ser y en el saber.

\section{Intervención en la comunidad a través del grupo piloto transformador}

Se seleccionó por muestreo no aleatorio, por conveniencia, el grupo noveno de la institución educativa que está conformado por 18 estudiantes, los cuales se codifican en la tabla 5 . 
La distribución del grupo por género corresponde a 13 mujeres (72\%) y 5 hombres (28\%), las edades de los estudiantes están entre 13 y 17 años; el nivel de estratificación es I y II. El núcleo familiar está compuesto por padre o madre, hermanos y abuelos; en un $60 \%$ conviven con los padres, un $20 \%$ con madre o padre, y un $20 \%$ con los abuelos.

El grupo estuvo conformado por estudiantes muy activos físicamente por la costumbre del trabajo y las caminatas que hacen a diario, en la zona rural deben realizar diferentes actividades que implican trabajos y continúo esfuerzo físico. Para la evaluación de las estrategias didácticas por parte de los docentes, se trabajó con la población del grado noveno, que corresponde a 9 docentes y 18 estudiantes. Dado que las poblaciones son pequeñas, en cada caso se trabajó con el $100 \%$ de los actores quienes se convierten en agentes de cambio en el interior de la institución.

\section{Diseño y Validación de instrumentos}

Se elaboraron dos encuestas, una para indagar a estudiantes sobre el tipo de actividades que desarrollaban los docentes en el aula y la pertinencia de las mismas. Además, los estudiantes propusieron actividades que a su consideración facilitan su aprendizaje. Las categorías de análisis se establecieron de manera inductiva con base en las respuestas de los estudiantes, referidas a las actividades que les gustaría que implementaran los docentes para aprender (Ver anexo 1), y otra para sondear la opinión de los profesores sobre las estrategias didácticas implementadas en sus clases y las que le gustaría implementar, con base en la socialización que en la institución se adelantó sobre inteligencias múltiples.

La validación de los instrumentos se realizó con 2 estudiantes y 2 profesores como una prueba piloto que se constituye en la validación en campo. Se considera validación de expertos la realizada por las investigadoras que ya han usado este tipo de instrumentos en el diagnósticos de otras áreas.

\section{Técnicas de análisis}

La información recolectada se agrupó de acuerdo con la pertinencia por categorías, que describen las estrategias pedagógicas y didácticas implementadas en el aula, se presenta en tablas de frecuencia y en algunos casos el porcentaje que éstas representan. Se muestra en gráficos las informaciones más homogéneas.

\section{Variable: estrategias pedagógicas tradicionales}

La variable estrategias pedagógicas tradicionales se discrimina de la siguiente manera:

1. El estudiante no es el protagonista del proceso.

2. Es un agente pasivo que recibe información.

3. No propone actividades.

4. El conocimiento se transmite. 
5. El docente posee el conocimiento.

6. El aprendizaje depende de la atención prestada por el estudiante o alumno.

7. El aprendizaje no se relaciona directamente a una actividad de tipo social.

8. Bajo la pedagogía tradicional, las estrategias didácticas que se implementan. están dirigidas a llamar la atención hacia el profesor porque él es quien posee el conocimiento y se asocian a la concepción de transmisión del conocimiento.

\section{Resultados y análisis}

\section{Encuesta para estudiantes}

Item 1. Escriba frente a cada asignatura el nombre de la actividad que más le agrada de las que emplea el docente, tenga en cuenta la frecuencia de uso indicada.

A los estudiantes se les indagó sobre las actividades que más les agrada, porque en la validación de los instrumentos no se identificó claramente el concepto de estrategia didáctica. La valoración de las estrategias didácticas implementadas por asignatura para los 9 docentes, que intervienen en este proceso, se describe en las figuras del 4 al 10.

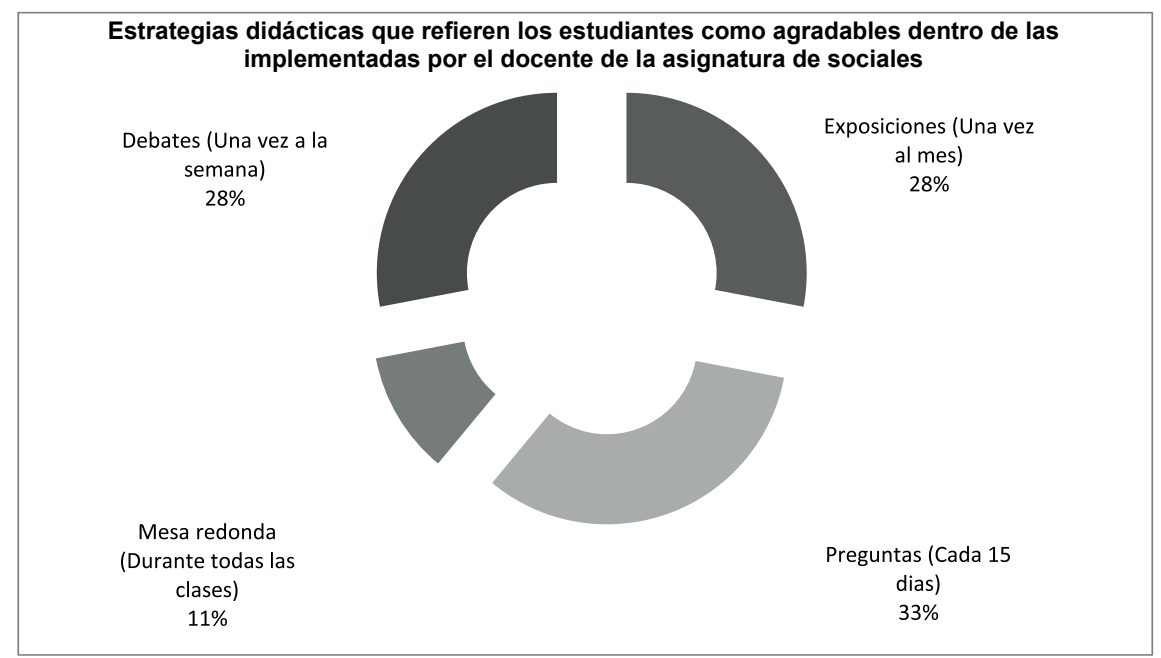

Figura 4. Actividades más agradables que emplea el docente de sociales en el aula y su frecuencia de uso

Mesa redonda y debates son las estrategias didácticas predilectas por los estudiantes en la asignatura de sociales; estas estrategias favorecen el desarrollo de la inteligencia lingüística o verbal. 


\section{María Cristina Gamboa Mora, Yenny García Sandoval, Marlén Beltrán Acosta}

Estrategias pedagógicas y didácticas para el desarrollo de las inteligencias múltiples y el aprendizaje autónomo. Artículo original producto de la investigación.

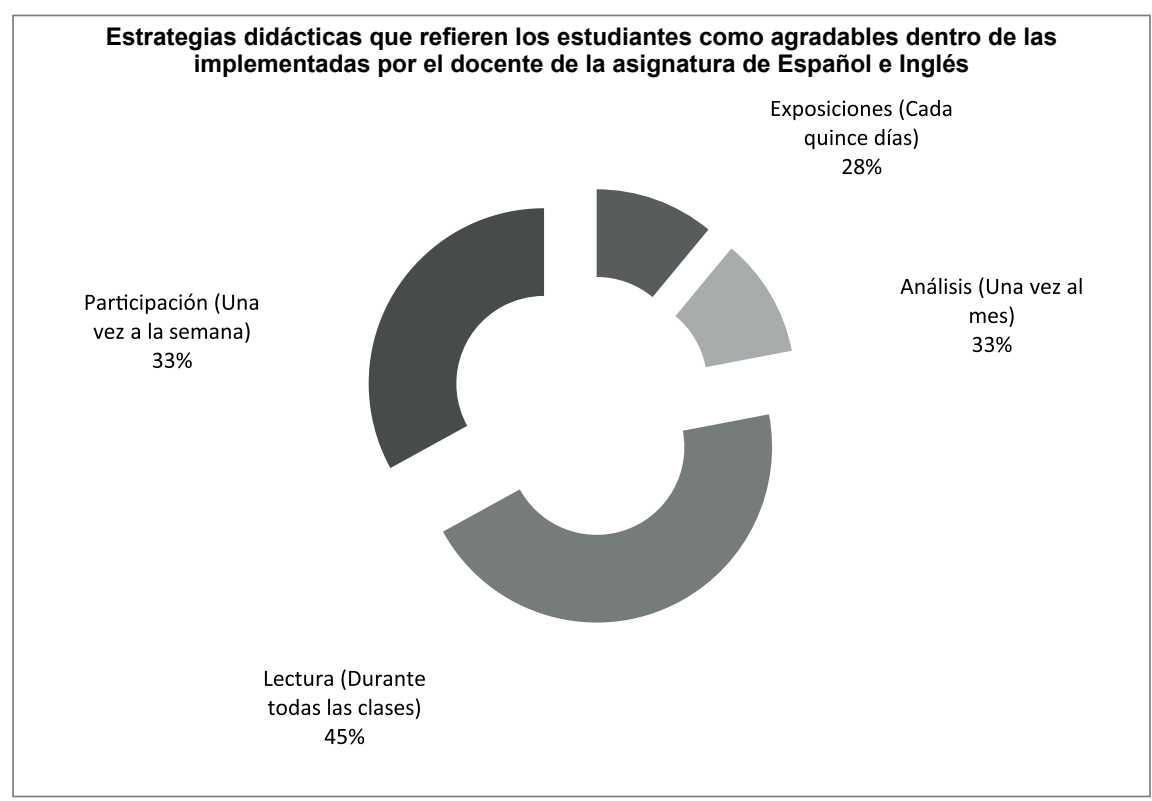

Figura 5. Actividades más agradables que emplea el docente de Español e Inglés en el aula y su frecuencia de uso

Lectura y exposiciones son las estrategias didácticas predilectas por los estudiantes en la asignatura de español e inglés; estas estrategias favorecen, esencialmente, el desarrollo de la inteligencia lingüistica o verbal.

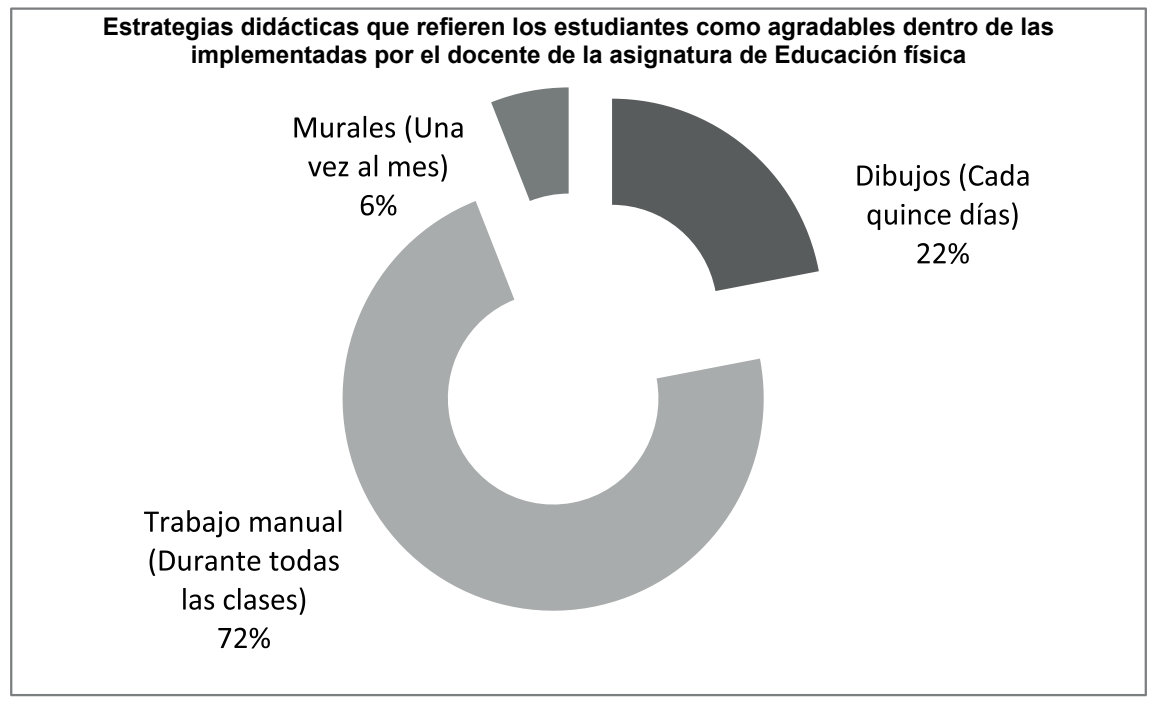

Figura 6. Actividades más agradables que emplea el docente de Educación física en el aula y su frecuencia de uso. Fuente: este trabajo.

Las estrategias didácticas denominadas ejercicios y juego contribuyen, primordialmente, al desarrollo de la inteligencia cenestésica corporal. La consulta de teoría contribuye a la competencia lingüística. 


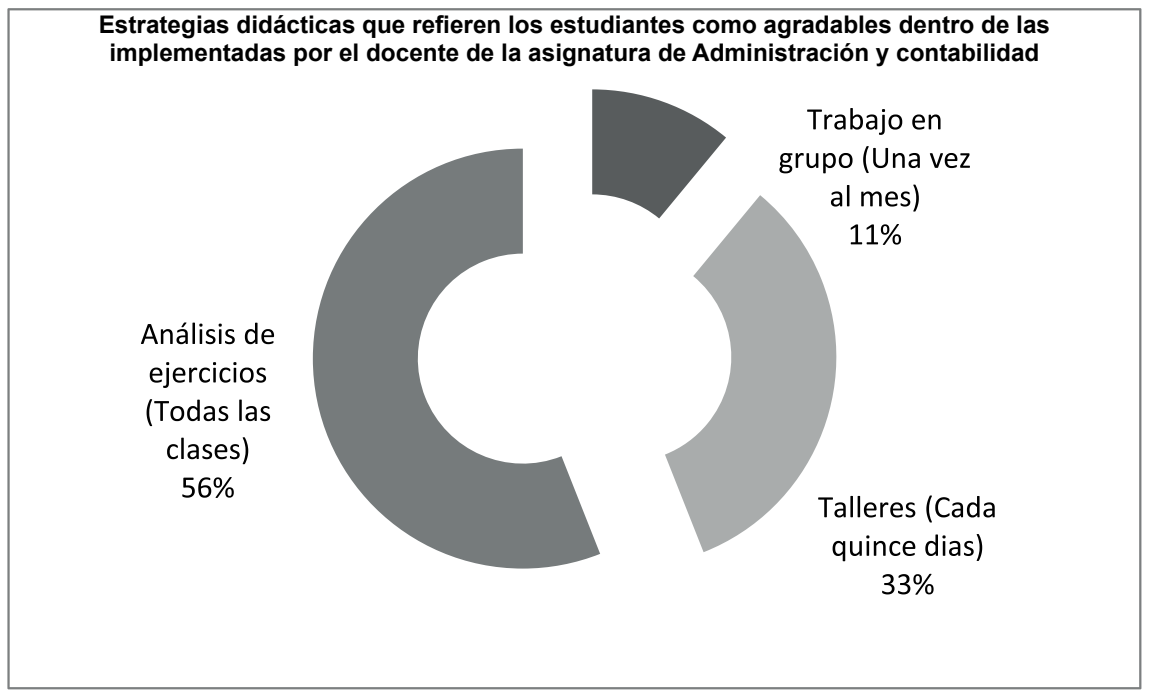

Figura 7. Actividades más agradables que emplea el docente de administración y contabilidad en el aula y su frecuencia de uso. Fuente: Este trabajo

De acuerdo con las estrategias didácticas reportadas para las asignaturas de administración y contabilidad, se ejercitan, principalmente, la inteligencia interpersonal, intrapersonal, la lingüística y la lógica matemática para resolver los ejercicios numéricos planteados.

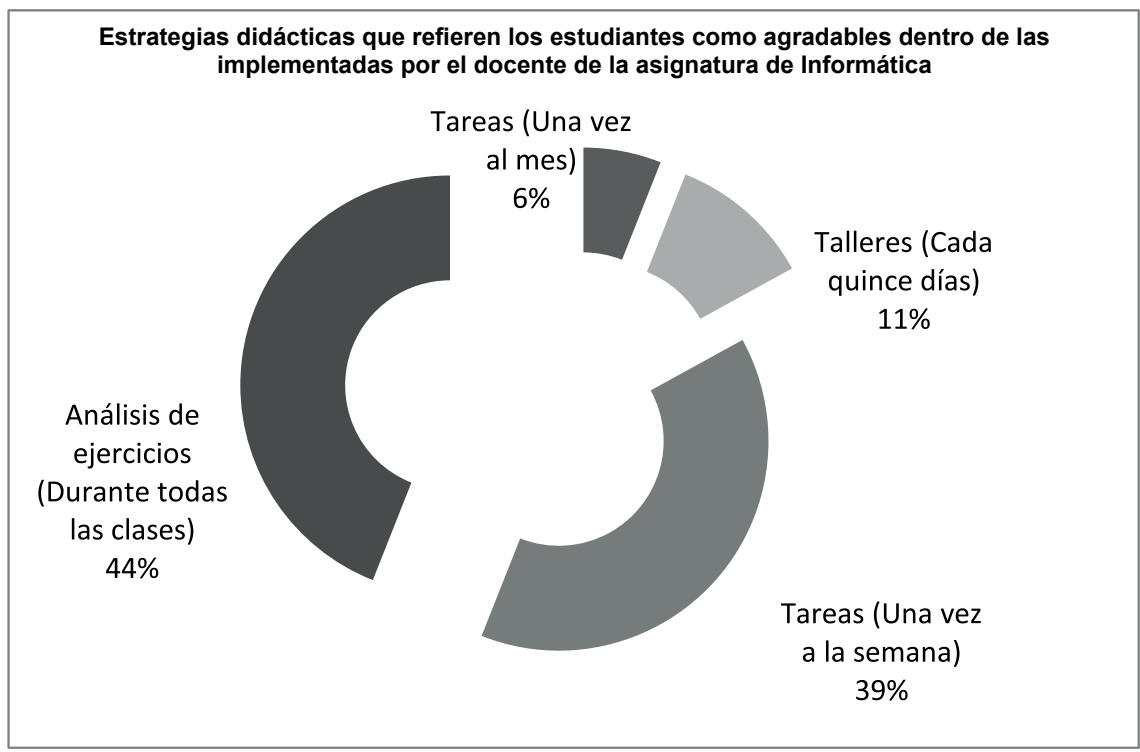

Figura 8. Actividades más agradables que emplea el docente de informática en el aula y su frecuencia de uso.

Las estrategias didácticas reportadas para la asignatura de informática contribuyen en la ejercitación de las siguientes inteligencias: interpersonal, intrapersonal, la lingüística y la lógica digital para resolver los ejercicios numéricos planteados. 


\section{María Cristina Gamboa Mora, Yenny García Sandoval, Marlén Beltrán Acosta}

Estrategias pedagógicas y didácticas para el desarrollo de las inteligencias múltiples y el aprendizaje autónomo. Artículo original producto de la investigación.

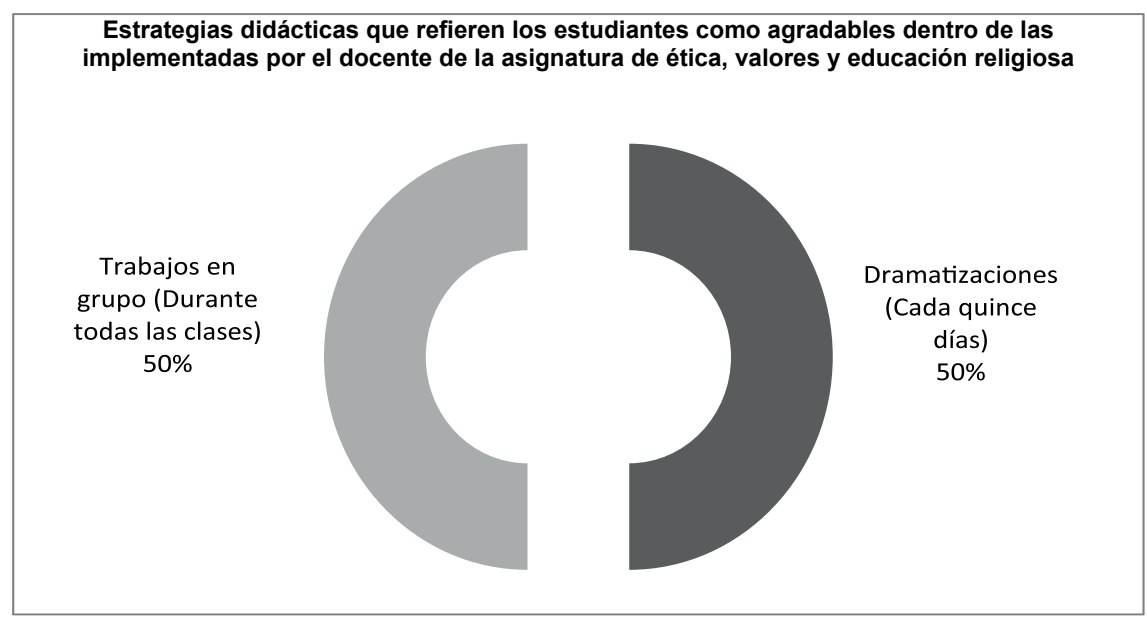

Figura 9. Actividades más agradables que emplea el docente de ética, valores y educación religiosa en el aula y su frecuencia de uso

Las dramatizaciones y el trabajo en equipo, que son las estrategias didácticas predilectas por los estudiantes en la asignatura de ética y valores, y educación religiosa; favorecen, primordialmente, el desarrollo de la inteligencia lingüística o verbal, la sexual, la interpersonal, interpersonal y la existencial o espiritual por el contexto en la que se desarrollan.

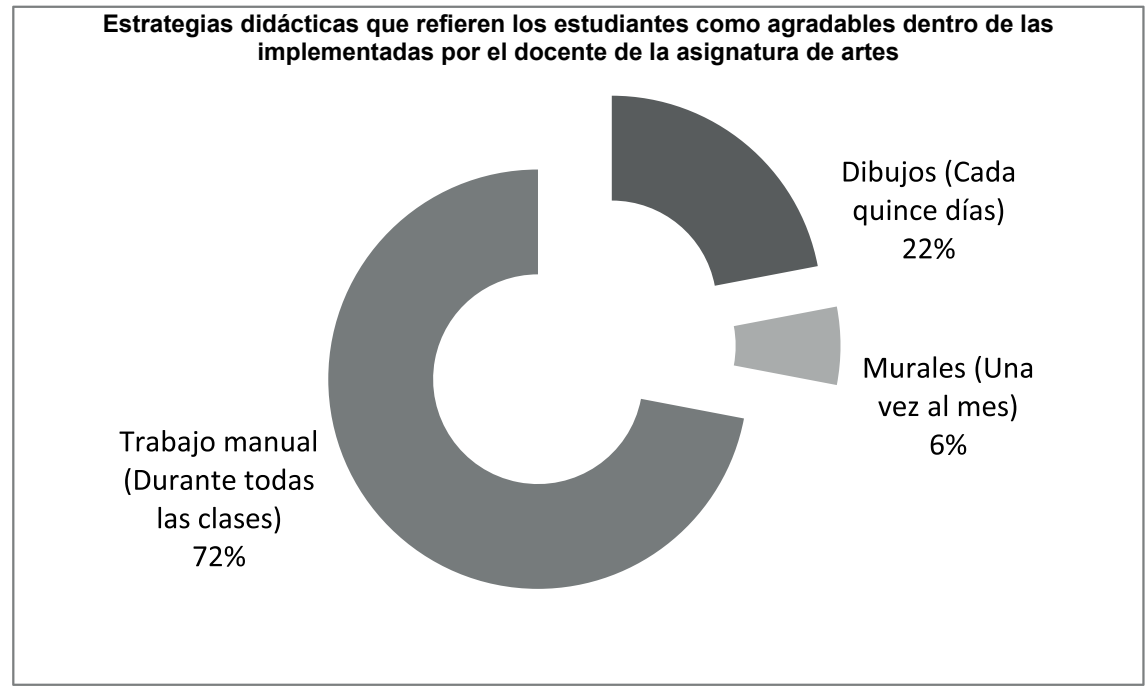

Figura 10. Actividades más agradables que emplea el docente de artes en el aula y su frecuencia de uso

Las estrategias didácticas reportadas para la asignatura de artística contribuyen, en la ejercitación de las siguientes inteligencias: pictórica y espacial. 


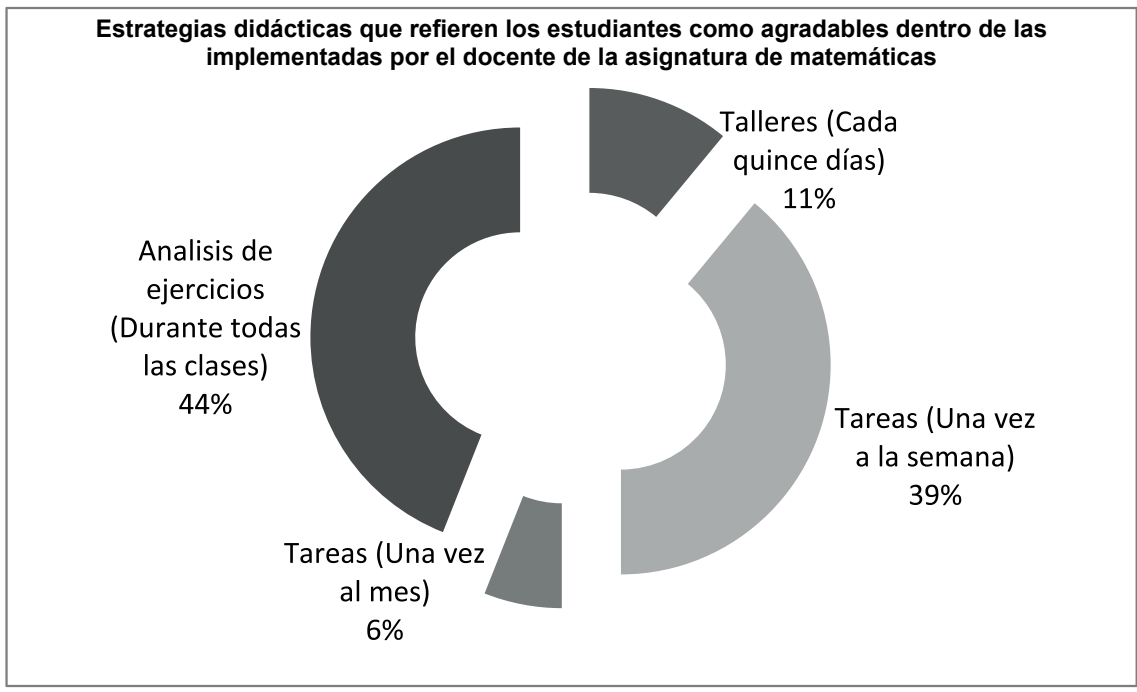

Figura 11. Actividades más agradables que emplea el docente de matemática en el aula y su frecuencia de uso.

De acuerdo con las estrategias didácticas reportadas para la asignatura de matemáticas, se ejercitan, principalmente, la inteligencia lógico matemática para resolver los ejercicios numéricos planteados.

Ítem 2 Complete la siguiente información, respecto con cómo cree se puede aprender en cada asignatura.

Tabla 3. Frecuencia de las actividades que los estudiantes reportan para aprender en las diferentes asignaturas

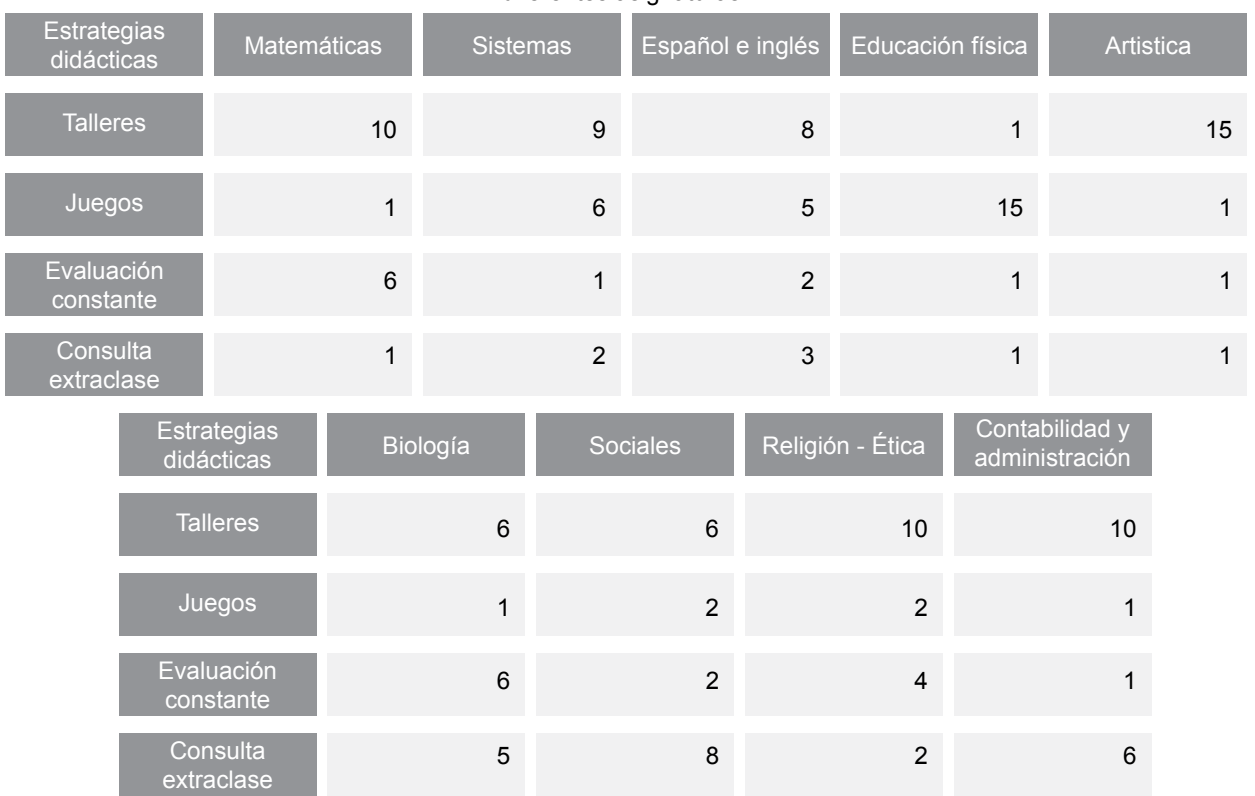

Nota: Datos procesados producto del proceso de investigación. 


\section{María Cristina Gamboa Mora, Yenny García Sandoval, Marlén Beltrán Acosta}

Estrategias pedagógicas y didácticas para el desarrollo de las inteligencias múltiples

y el aprendizaje autónomo. Artículo original producto de la investigación.

De acuerdo con la información recolectada en este ítem, no hay una asociación directa entre las actividades reportadas como las que más le agradan a los estudiantes, y las que refieren para aprender; solo relacionaron cuatro estrategias didácticas que deben estar en correspondencia con la concepción que ellos tienen de aprendizaje. Con la información recolectada no se observa una gama amplia de estrategias didácticas que favorezcan el aprendizaje autónomo. Los estudiantes no refieren un porqué de su selección.

Ítem 3 Escriba el nombre de las actividades que le gustaría que sus profesores pusieran en práctica para aprender en las clases.

Tabla 4. Actividades que los estudiantes quieren que los profesores pongan en práctica para aprender

\begin{tabular}{|c|c|c|}
\hline $\begin{array}{c}\text { Estrategias didácticas } \\
\text { para aprender }\end{array}$ & Frecuencia & Propósito \\
\hline Exposiciones & 3 & Saber exponer \\
\hline Explicación & 6 & $\begin{array}{r}\text { Para mejorar } \\
\text { la expresión oral }\end{array}$ \\
\hline Análisis & 2 & $\begin{array}{r}\text { Para comprender } \\
\text { mejor un texto }\end{array}$ \\
\hline Actividades lúdicas & 6 & $\begin{array}{r}\text { Menos escritura } \\
\text { más práctico }\end{array}$ \\
\hline $\begin{array}{c}\text { Lectura del manual de } \\
\text { convivencia }\end{array}$ & 1 & $\begin{array}{r}\text { Para conocer los } \\
\text { derechos y deberes }\end{array}$ \\
\hline
\end{tabular}

\section{Encuesta para profesores o docentes}

Ítem 1. Señale con una X cuál o cuáles le gustaría implementar en el desarrollo de su asignatura.

Tabla 5. Estrategias didácticas que seleccionan los docentes dentro de las propuestas para implementar

\section{Estrategias didácticas}

Durante todas las clases

Una vez a la semana

Cada quince dias

Una vez al mes

Estrategias didácticas

Cada quince dias

Una vez al mes

\section{Español e inglés}

Técnicas para resolver problemas, debate simposio y mesa redonda

Juegos, carteles, murales y dibujos libres; desarrollo de una actividad propuesta por los estudiantes y composición de rondas y coplas

Cuentos, dramatizaciones, sopa de letras y crucigramas

Club de revistas, adivinanzas y acertijos

\section{Matemáticas}

Técnicas para resolver problemas B18

Debates, simposio, mesa redonda y desarrollo de una actividad propuesta por los estudiantes 
Estrategias didácticas

Cada quince dias

Una vez al mes

Estrategias didácticas

Una vez a la semana

Una vez al mes

Estrategias didácticas

Una vez a la semana

Cada quince dias

Una vez al mes

Estrategias didácticas

Una vez a la semana

Una vez al mes

Estrategias didácticas

Una vez a la semana

Estrategias didácticas

Durante todas las clases

Una vez a la semana

Estrategias didácticas

Cada quince dias

Una vez al mes

\section{Artistica}

Carteles, murales, dibujos libres

Desarrollo de una propuesta por los estudiantes

Ética y valores - Educación religiosa

\section{Crucigramas}

Juegos adivinanzas y acertijo, cunetos y dramatizaciones; una actividad propuesta por los estudiantes

\section{Contabilidad y administración}

Técnica para resolver problemas

Desarrollo de una propuesta por los estudiantes

Club de revistas

\section{Sociales}

Debates, simposio, mesa redonda y desarrollo de una actividad propuesta por los estudiantes

Club de revistas y elaboración de murales

\section{Informática}

Desarrollo de una actividad propuesta por los estudiantes y composición de rondas

\section{Educación física}

Juegos

Desarrollo de una actividad propuesta por los estudiantes

\section{Biología}

Debates, simposio, mesa redonda y desarrollo de una actividad propuesta por los estudiantes

Sopa de letras

Los nueve docentes que participaron en el estudio seleccionan como estrategia didáctica, incluir una actividad propuesta por los estudiantes; esto permitiría autonomía de los estudiantes en su proceso de enseñanza-aprendizaje. 


\section{María Cristina Gamboa Mora, Yenny García Sandoval, Marlén Beltrán Acosta}

Estrategias pedagógicas y didácticas para el desarrollo de las inteligencias múltiples

y el aprendizaje autónomo. Artículo original producto de la investigación.

\section{Ítem 2 Descripción de habilidades y nivel de socialización de los estudiantes}

Tabla 5. Descripción de la población de grado noveno por parte de los docentes

\begin{tabular}{|c|c|c|c|}
\hline CÓDIGO & GÉNERO & $\begin{array}{c}\text { Nivel de } \\
\text { socialización }\end{array}$ & Habilidades \\
\hline $\begin{array}{l}\text { Estudiante } 1 . \\
\text { ACJS }\end{array}$ & $\mathrm{F}$ & Alto & $\begin{array}{l}\text { Compañerista, Comunicativa, Sociable, } \\
\text { Responsable e Inteligente }\end{array}$ \\
\hline $\begin{array}{l}\text { Estudiante } 2 . \\
\text { CJAC }\end{array}$ & $F$ & Bajo & $\begin{array}{l}\text { Respetuosa, Amable, Humilde, Atenta e } \\
\text { Inteligente }\end{array}$ \\
\hline $\begin{array}{l}\text { Estudiante } 3 . \\
\text { DUS }\end{array}$ & M & Alto & $\begin{array}{l}\text { Inteligente, Deportista, Amable, } \\
\text { Compañerista y Extrovertido }\end{array}$ \\
\hline $\begin{array}{l}\text { Estudiante } 4 . \\
\text { GHDK }\end{array}$ & $F$ & Bajo & $\begin{array}{l}\text { Respetuosa, Compañerista, Atenta, } \\
\text { Honrada y Pasiva }\end{array}$ \\
\hline $\begin{array}{l}\text { Estudiante } 5 . \\
\text { JGBD }\end{array}$ & $F$ & Bajo & $\begin{array}{l}\text { Amable, Bondadosa, Respetuosa, } \\
\text { Cariñosa; Deportista }\end{array}$ \\
\hline $\begin{array}{l}\text { Estudiante } 6 . \\
\text { JGJA }\end{array}$ & M & Bajo & $\begin{array}{l}\text { Respetuoso, Amable, Responsable, } \\
\text { Tierno, Pasivo }\end{array}$ \\
\hline $\begin{array}{l}\text { Estudiante } 7 . \\
\text { JGMP }\end{array}$ & $F$ & Bajo & $\begin{array}{l}\text { Respetuosa, Amable, Responsable, } \\
\text { Tierna, y, Pasiva }\end{array}$ \\
\hline $\begin{array}{l}\text { Estudiante } 8 . \\
\text { LPDF }\end{array}$ & M & Bajo & $\begin{array}{l}\text { Inteligente, Ágil, Compañerista, Puntual } \\
\text { y Responsable }\end{array}$ \\
\hline $\begin{array}{l}\text { Estudiante } 9 . \\
\text { LPGA }\end{array}$ & $F$ & Alto & $\begin{array}{l}\text { Inteligente, Amable, Compañerista, } \\
\text { Colaboradora y Sociable }\end{array}$ \\
\hline $\begin{array}{l}\text { Estudiante } \\
\text { 10. MAC }\end{array}$ & $\mathrm{F}$ & Alto & $\begin{array}{l}\text { Respetuosa, Compañerista, Sociable, } \\
\text { Tierna y Observadora }\end{array}$ \\
\hline $\begin{array}{l}\text { Estudiante } \\
\text { 11. MCDA }\end{array}$ & M & Bajo & $\begin{array}{l}\text { Pasivo, Respetuoso, Prudente, } \\
\text { Mesurado y Tolerante }\end{array}$ \\
\hline $\begin{array}{l}\text { Estudiante } \\
\text { 12. PCAM }\end{array}$ & $\mathrm{F}$ & Alto & $\begin{array}{l}\text { Líder, Deportista, Inteligente, Puntual y } \\
\text { Sociable }\end{array}$ \\
\hline $\begin{array}{l}\text { Estudiante } \\
\text { 13.PPJA }\end{array}$ & M & Bajo & $\begin{array}{l}\text { Respetuoso, Pasivo, Amable, Tolerante } \\
\text { y Tierno }\end{array}$ \\
\hline $\begin{array}{l}\text { Estudiante } \\
\text { 14. RBNY }\end{array}$ & $F$ & Bajo & $\begin{array}{l}\text { Respetuosa, Amable, Responsable, } \\
\text { Sensible y Tierna }\end{array}$ \\
\hline $\begin{array}{l}\text { Estudiante } \\
15 . \text { RJSM }\end{array}$ & $\mathrm{F}$ & Alto & $\begin{array}{l}\text { Responsable, Puntual, Creativa, } \\
\text { Inteligente y Deportista }\end{array}$ \\
\hline $\begin{array}{l}\text { Estudiante } \\
\text { 16. RDN }\end{array}$ & $F$ & Bajo & $\begin{array}{l}\text { Puntual, Atenta, Respetuosa, Pasiva y } \\
\text { Tolerante }\end{array}$ \\
\hline $\begin{array}{l}\text { Estudiante } \\
\text { 17. UYZ }\end{array}$ & $F$ & Alto & $\begin{array}{l}\text { Líder, Extrovertida, Atenta, Responsable } \\
\text { y Sociable }\end{array}$ \\
\hline $\begin{array}{l}\text { Estudiante } \\
\text { 18. VPNM }\end{array}$ & $\mathrm{F}$ & Alto & $\begin{array}{l}\text { Líder, Cariñosa, Sociable, Tolerante e } \\
\text { Inteligente }\end{array}$ \\
\hline
\end{tabular}

Las habilidades que reconocen los docentes en sus estudiantes no corresponden a las habilidades requeridas para la solución de problemas; las habilidades reportadas corresponden a cualidades que perciben de sus estudiantes y se relacionan más con sus cualidades comportamentales.

El nivel de socialización general y por género se presenta en la figura 12. Se encuentra como característica de la población en estudio, que los hombres pertenecientes al estudio tienen un bajo nivel de socialización comparado con el de las mujeres $(20 \%$ vs $54 \%)$. 
Nivel de socialización en grado noveno de la institución Marco Fidel Suárez

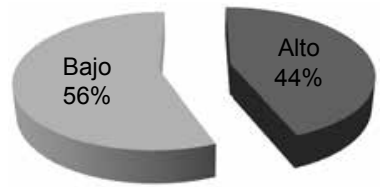

Nivel de socialización de las mujeres de grado noveno Suarez
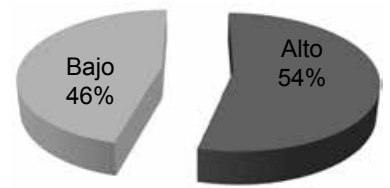

Nivel de socialización de los hombres de grado noveno Suarez

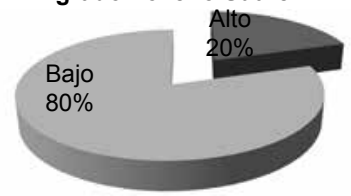

Figura 12. Nivel de socialización población estudiantil

\section{Ítem 3 Escriba cinco actividades que utiliza en su clase para promover el aprendizaje de sus estudiantes.}

Tabla 6. Relación de estrategias didácticas que emplean los docentes para promover el aprendizaje de sus estudiantes por asignatura

\begin{tabular}{|c|c|c|c|}
\hline Asignaturas & Estrategias didácticas & Asignaturas & Estrategias didácticas \\
\hline Biología & $\begin{array}{l}\text {-Análisis de ejercicios } \\
\text {-Explicación } \\
\text {-Aclaración } \\
\text {-Desarrollo de talleres } \\
\text {-Tareas }\end{array}$ & Informática & $\begin{array}{l}\text {-Talleres } \\
\text {-Exposiciones } \\
\text {-Trabajo grupal } \\
\text {-Prácticas } \\
\text {-Juegos }\end{array}$ \\
\hline $\begin{array}{l}\text { Educación } \\
\text { física }\end{array}$ & $\begin{array}{l}\text {-Socialización referentes teóricos } \\
\text {-Incorporación de la teória a la práctica } \\
\text {-Realización de ejercicios específicos } \\
\text {-Retroalimentación de lo realizado } \\
\text {-Aplicación de trabajos en grupo o } \\
\text { individualmente }\end{array}$ & Sociales & $\begin{array}{l}\text {-Lecturas } \\
\text {-Exposiciones } \\
\text {-Análisis } \\
\text {-Localización } \\
\text {-Observación }\end{array}$ \\
\hline $\begin{array}{l}\text { Inglés y } \\
\text { lenguaje }\end{array}$ & $\begin{array}{c}\text {-Dramatizaciones } \\
\text {-Comprensión de lectura } \\
\text {-Elaboración escritural } \\
\text {-Relatorías } \\
\text {-Consultas } \\
\text {-Talleres grupales e individuales } \\
\text {-Ejercicios Listening }\end{array}$ & $\begin{array}{l}\text { Ética, valores } \\
\text { y educación } \\
\text { religiosa }\end{array}$ & $\begin{array}{l}\text {-Talleres } \\
\text {-Trabajo grupal } \\
\text {-Sopa de letras } \\
\text {-Análisis de lecturas } \\
\text {-Dramatizaciones }\end{array}$ \\
\hline \multirow[t]{2}{*}{$\begin{array}{l}\text { Administración } \\
\text { y contabilidad }\end{array}$} & $\begin{array}{l}\text {-Análisis de lecturas } \\
\text {-Talleres } \\
\text {-Exposiciones } \\
\text {-Análisis de ejercicios } \\
\text {-Tareas }\end{array}$ & Artística & $\begin{array}{l}\text {-Trabajos manuales } \\
\text {-Composición } \\
\text {-Dibujos } \\
\text {-Crucigramas } \\
\text {-Talleres }\end{array}$ \\
\hline & & Matemáticas & $\begin{array}{c}\text {-Talleres } \\
\text {-Análisis de ejercicios } \\
\text {-Tareas } \\
\text {-Trabajo individual y grupal }\end{array}$ \\
\hline
\end{tabular}


Con base en las respuestas de los estudiantes se seleccionan por afinidad las estrategias didácticas implementadas en el aula, y se valoran de acuerdo con su frecuencia y el porcentaje que representan.

\begin{tabular}{|c|c|c|c|c|c|}
\hline $\begin{array}{l}\text { Estrategias didácticas } \\
\text { implementadas }\end{array}$ & Frecuencia & Porcentaje & $\begin{array}{l}\text { Estrategias didácticas } \\
\text { implementadas }\end{array}$ & Frecuencia & Porcentaje \\
\hline $\begin{array}{l}\text { Análisis de } \\
\text { actividades }\end{array}$ & 4 & 8,9 & Juegos & 1 & 2,2 \\
\hline $\begin{array}{l}\text { Aclaración o } \\
\text { explicación }\end{array}$ & 2 & 4,4 & Lecturas & 1 & 2,2 \\
\hline Composición & 1 & 2,2 & Localización & 1 & 2,2 \\
\hline $\begin{array}{c}\text { Comprensión de } \\
\text { lectura }\end{array}$ & 3 & 6,7 & Observación & 1 & 2,2 \\
\hline Consultas & 1 & 2,2 & Prácticas & 1 & 2,2 \\
\hline Crucigramas & 1 & 2,2 & $\begin{array}{c}\text { Realización de } \\
\text { ejercicios específicos }\end{array}$ & 1 & 2,2 \\
\hline Dibujos & 1 & 2,2 & Relatorías & 1 & 2,2 \\
\hline Dramatizaciones & 2 & 4,4 & $\begin{array}{l}\text { Socialización } \\
\text { referentes teóricos }\end{array}$ & 1 & 2,2 \\
\hline Ejercicios Listening & 1 & 2,2 & Sopa de letras & 1 & 2,2 \\
\hline Elaboración escritural & 1 & 2,2 & $\begin{array}{l}\text { Talleres grupales e } \\
\text { individuales }\end{array}$ & 9 & 20,0 \\
\hline Exposiciones & 4 & 8,9 & Tareas & 4 & 8,9 \\
\hline $\begin{array}{l}\text { Incorporación de la } \\
\text { teória a la práctica }\end{array}$ & 1 & 2,2 & Trabajos manuales & 1 & 2,2 \\
\hline
\end{tabular}

Las cinco estrategias didácticas que predominantemente utilizan los profesores del grado noveno de la institución educativa objeto de estudio, son: talleres grupales o individuales, exposiciones, análisis de actividades, tareas y comprensión de lectura, las cuales favorecen la inteligencia lingüística de acuerdo con la teoría de Gardner. No se evidencia una pedagogía que propenda por el aprendizaje autónomo.

\section{Conclusiones}

Las estrategias didácticas referidas por los estudiantes para aprender corresponden a una pedagogía tradicional y no se relacionan con estrategias didácticas que favorezcan el aprendizaje autónomo.

Los estudiantes del grado noveno de la institución refieren los talleres como el mecanismo predilecto para aprender en clase.

La evaluación de las estrategias pedagógicas permitió a los docentes tomar conciencia de la importancia de emplear nuevas estrategias en su que hacer pedagógico para así poder innovar y mejorar en el proceso de aprendizaje de los estudiantes. 
Con el conocimiento de la teoría de las inteligencias múltiples y el reconocimiento de las actividades planteadas en clase, los docentes pueden seleccionar de manera consciente las estrategias didácticas que necesitan para fomentar la pedagogía del aprendizaje autónomo.

Los estudiantes reconocieron la existencia de las inteligencias múltiples y cómo estas pueden articularse en el desarrollo de las asignaturas. De igual manera, se evidenció una motivación por el desarrollo de las mismas con el fin de promover el aprendizaje autónomo.

Por otro lado, las concepciones de los docentes determinan su desempeño en el aula y de ellas depende la selección de las estrategias pedagógicas y didácticas que intervienen en el proceso de enseñanza aprendizaje.

Los docentes al reconocer las estrategias pedagógicas y didácticas que promueven cada una de las inteligencias múltiples y el aprendizaje autónomo, pueden realizar una planeación pedagógica consciente que permita la construcción individual y social de conocimientos.

Los docentes comprenden la necesidad de aplicar diferentes estrategias que fomenten el desarrollo de la autonomía en cada estudiante.

En instituciones pequeñas como la institución objeto de estudio, es fácil conocer a los estudiantes y sus habilidades, lo cual permite una planeación pedagógica adecuada y acorde con las necesidades de su población (En 2011, la población fue de 160 estudiantes; 18 estudiantes en grado noveno).

Los estudiantes manifestaron interés y mostraron una actitud positiva frente a las actividades que permiten desarrollar el aprendizaje autónomo.

La implementación de estrategias para el desarrollo de las inteligencias múltiples permite transformar la pedagogía tradicional en la medida en que los docentes son conscientes del cambio necesario en la concepción de aprendizaje y su consecuente implementación de métodos de enseñanza activos y participativos que propenden por el aprendizaje autónomo.

En el proceso de enseñanza-aprendizaje lo más importante es que el estudiante reconozca la vía para solucionar problemas en el contexto escolar y fuera de él. El proceso desarrollado permitió a los docentes aportar a su autorreconocimiento, al explicitar o hacer conscientes sus percepciones, dinámicas y su propia concepción de aprendizaje; por lo tanto, de uno u otro modo, este tipo de ejercicios contribuye a desarrollar su autonomía en el aula, a innovar y a dejar atrás prácticas anquilosadas en los procesos de enseñanza aprendizaje. 


\section{Proyección de la investigación en la institución educativa}

Una vez socializado el tema de la teoría de inteligencias múltiples a la comunidad académica, se espera que los docentes y estudiantes implementen estrategias pedagógicas y didácticas que contribuyan al desarrollo de las inteligencias múltiples propuestas en la teoría de Gadner, con el fin de potencializar las habilidades de sus estudiantes y generen en el aula la construcción de conocimientos que les permita resolver problemas.

\section{Referencias bibliográficas}

Ander, E. (2006). Claves para introducirse en el estudio de las inteligencias múltiples. Argentina: HomoSapiens.

Antunes, C. (2000). Estimular las inteligencias múltiples: Qué son, cómo se manifiestan, como funcionan. Madrid: Narcea S.A.

Bravo, H. (2008). Estrategias pedagógicas. Córdoba: Universidad del Sinú.

Fondo de cultura México. (1987, Sep. 23) Las inteligencias múltiples en el siglo XXI. Recuperado de: www.infoamerica.org/teoria/bandura1.htm

Gamboa, M. (2004). Diagnóstico sobre las concepciones que tienen los profesores y estudiantes de las Facultades de Salud e Ingeniería de la Fundación Universitaria Manuela Beltrán acerca de las prácticas de Laboratorio de Química. Tesis de Maestría en Docencia de la Química. Bogotá-Colombia: Universidad Pedagógica Nacional, Bogotá: UPN.

Gamboa, M, Sánchez, D y Briceño J. (2009). La planeación pedagógica como estrategia de investigación para fortalecer la formación científica de los estudiantes en las áreas de Ciencias Básicas de la Universidad Manuela Beltrán. En: Tecné, Episteme y Didaxis, $T E A$, Número Extra. Páginas 826-832.

Gómez G. (2001). Investigación Seminario de Epistemología. CENCAD Fundación Universitaria Los Libertadores. Bogotá-Colombia: FUL.

Gardner, H. (1983). Estructuras de la mente: la teoría de las múltiples inteligencias. México: Fondo de Cultura económica.

Gardner, H. (1999). Intelligence Reframed: Multiple Intelligences for the 21st Century. Basic Books. 


\section{Revista de}

Lapalma, F. (2008). Teoría de las inteligencias múltiples y la educación. Octubre 15. Recuperado de www.monografias.com

Manrique V, L. (s.f.). Aprendizaje autónomo. Recuperado de www.ateneonline.net Disponible en: http://ur1.ca/gagf6

Medina B, A. (2011). Inteligencias múltiples. Recuperado de http://ur1.ca/gaget

OCDE. (2010). Habilidades y competencias del siglo XXI para los aprendices del nuevo milenio en los países de la OCDE.

Ortiz de Maschwitz, E. M. (s.f.). Inteligencias Múltiples de la Educación de la Persona. Buenos Aires: Bonum.

UNAD. (2011). Proyecto Académico Pedagógico Solidario. Versión 3.o. Bogotá: UNAD.

\section{Anexo 1.}

\section{COLEGIO:}

\section{Apreciado Estudiante:}

Solicito su colaboración en el desarrollo de la siguiente encuesta sobre las estrategias pedagógicas y didácticas que implementan sus profesores en el aula.

1. Escriba frente a cada asignatura el nombre de la actividad que más le agrada de las que emplea el docente, tenga en cuenta la frecuencia de uso indicada.

\begin{tabular}{|l|l|l|l|l|}
\hline Actividad & $\begin{array}{l}\text { Durante todas } \\
\text { las clase }\end{array}$ & $\begin{array}{l}\text { Una vez a la } \\
\text { Semana }\end{array}$ & Cada Quince días & Una vez al mes \\
\hline Matemáticas & & & & \\
\hline Sistemas & & & \\
\hline $\begin{array}{l}\text { Lenguaje e } \\
\text { Inglés }\end{array}$ & & & \\
\hline Educación Física & & & \\
\hline Artística. & & & \\
\hline Biología & & & \\
\hline Sociales & & & \\
\hline Ética y Valores & & & \\
\hline $\begin{array}{l}\text { Educación } \\
\text { Religiosa }\end{array}$ & & & \\
\hline $\begin{array}{l}\text { Contabilidad y } \\
\text { Administración }\end{array}$ & & & \\
\hline
\end{tabular}


2. Complete la siguiente información, con respecto a cómo crees puedes aprender en cada asignatura, escriba el nombre de las actividades que considera le permiten aprender en las clases.

\begin{tabular}{|l|l|l|}
\hline \multicolumn{1}{|c|}{ Actividad } & Actividad que quisiera desarrollar & ¿Por qué? \\
\hline Matemáticas & & \\
\hline Sistemas & & \\
\hline Lenguaje e Inglés & & \\
\hline Educación Física & & \\
\hline Artística. & & \\
\hline Biología & & \\
\hline Sociales & & \\
\hline Ética y Valores & & \\
\hline Educación Religiosa & & \\
\hline Contabilidad y Administración & & \\
\hline
\end{tabular}

3. Escriba el nombre de las actividades que le gustaría que sus profesores pusieran en práctica para aprender en las clases

\begin{tabular}{|l|l|}
\hline Actividad & Proposito \\
\hline & \\
\hline & \\
\hline & \\
\hline
\end{tabular}

\section{Anexo 2.}

\section{COLEGIO:}

Apreciado Docente:

Solicito su colaboración en el desarrollo de la siguiente encuesta acerca de las estrategias pedagógicas que implementa y que le gustaría implementar en sus clases.

Asignatura que orienta:

1. De las siguientes actividades, señale con una $X$ cuál o cuáles le gustaría implementar en el desarrollo de su asignatura. 


\section{Revista de}

\begin{tabular}{|l|l|l|l|l|}
\hline Actividad & $\begin{array}{l}\text { Durante todas } \\
\text { las clase }\end{array}$ & $\begin{array}{l}\text { Una vez a la } \\
\text { Semana }\end{array}$ & $\begin{array}{l}\text { Cada Quince } \\
\text { dias }\end{array}$ & Una vez al mes \\
\hline $\begin{array}{l}\text { Técnicas para resolver } \\
\text { problemas. }\end{array}$ & & & \\
\hline Club de revistas. & & & \\
\hline Adivinanzas o acertijos. & & & \\
\hline Juegos. & & & \\
\hline $\begin{array}{l}\text { Carteles, murales, dibujos } \\
\text { libres. }\end{array}$ & & & \\
\hline $\begin{array}{l}\text { Debate, simposio, mesa } \\
\text { redonda. }\end{array}$ & & & \\
\hline $\begin{array}{l}\text { Desarrollo de una } \\
\text { actividad propuesta por los } \\
\text { estudiantes. }\end{array}$ & & & \\
\hline $\begin{array}{l}\text { Composición de rondas, } \\
\text { coplas. }\end{array}$ & & & \\
\hline Cuentos, dramatizaciones. & & & \\
\hline Sopa de letras. & & & \\
\hline Crucigramas. & & & \\
\hline
\end{tabular}

2. Complete la siguiente información:

\begin{tabular}{|c|c|c|}
\hline Nombre de los estudiantes & $\begin{array}{c}\text { Enuncie } 5 \text { habilidades del } \\
\text { estudiante }\end{array}$ & $\begin{array}{c}\text { Cuál es el nivel de } \\
\text { socialización de cada } \\
\text { estudiante (alto-bajo). }\end{array}$ \\
\hline & & \\
\hline & & \\
\hline
\end{tabular}

3. Escriba cinco actividades que utiliza en su clase para promover el aprendizaje de sus estudiantes.

\begin{tabular}{|l|c|}
\hline Actividad & Proposito \\
\hline & \\
\hline & \\
\hline & \\
\hline & \\
\hline
\end{tabular}




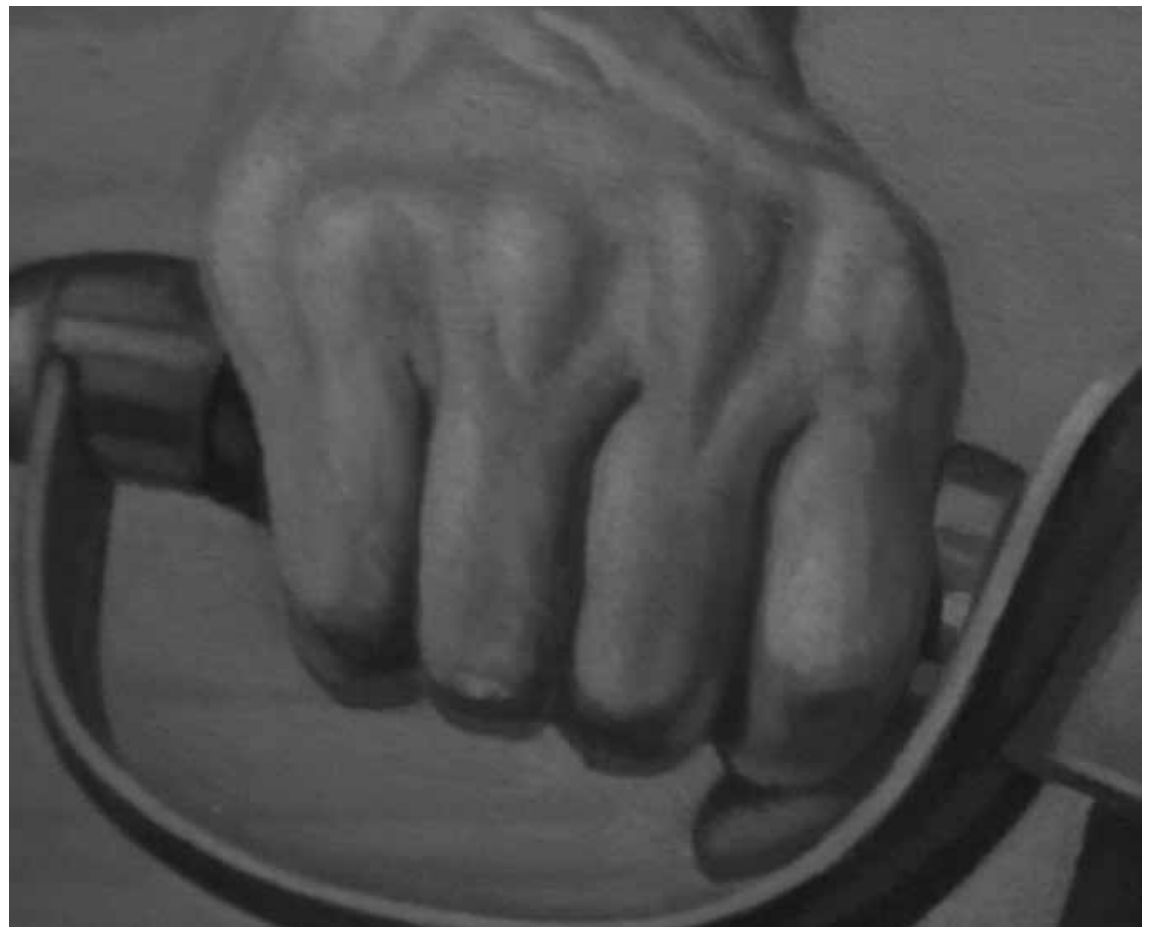

Fotografia: José Enrique Castillo 